
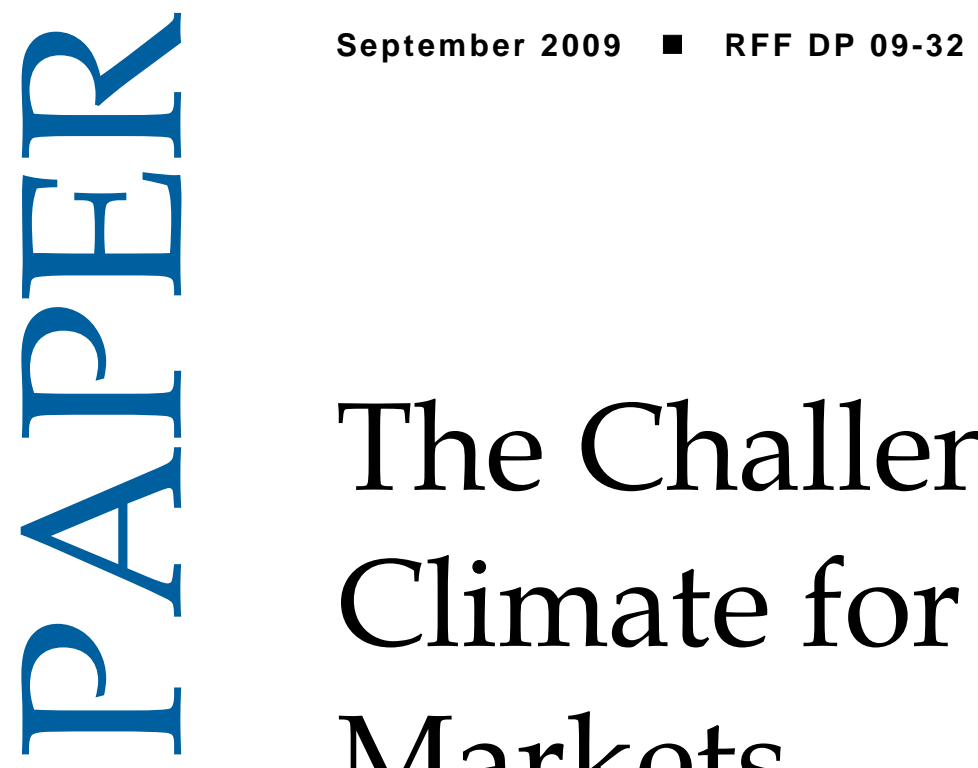

\title{
The Challenges of Climate for Energy Markets
}

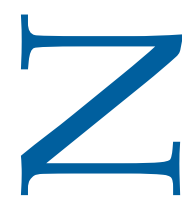

Timothy J. Brennan 


\title{
The Challenges of Climate for Energy Markets
}

\author{
Timothy J. Brennan
}

\begin{abstract}
Among the many complex issues of technology, governance, and market design affecting the electricity sector, climate policy has become dominant. From the perspective of a nonspecialist looking at this changing dominance, a quiz illuminates some of the peculiar uses of language one can find in climate change and energy efficiency policy. Six economic challenges are then examined: cap-and-trade vs. taxes, non-price regulations, energy efficiency policies, mitigation vs. adaptation, trade effects, and transmission planning. Three additional challenges affect not just the means to the climate policy end but also the end itself: the "fat tails" problem, discount rates, and whether environmental protection should be evaluated by aggregating willingness to pay across persons. Planners in the public and private sectors need to be aware of not only the economic policy challenges but also arguments that may influence the intensity of the climate policies with which they have to cope.
\end{abstract}

Key Words: climate change, energy policy, electricity

JEL Classification Numbers: Q54, Q48, L94

(C) 2009 Resources for the Future. All rights reserved. No portion of this paper may be reproduced without permission of the authors.

Discussion papers are research materials circulated by their authors for purposes of information and discussion. They have not necessarily undergone formal peer review. 


\section{Contents}

1. By Way of Introduction .................................................................................................. 1

II. First, a Quiz ..................................................................................................................................... 3

III. Economic Challenges .................................................................................................................. 6

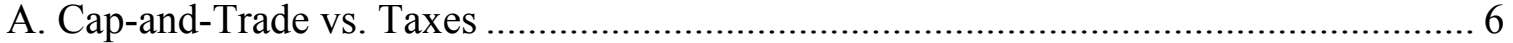

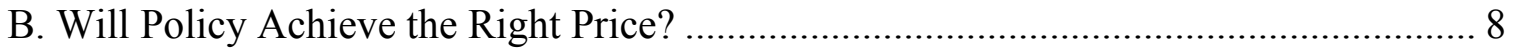

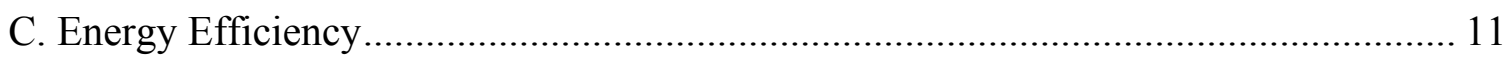

D. Mitigation vs. Adaptation ..................................................................................... 13

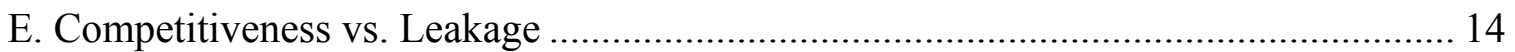

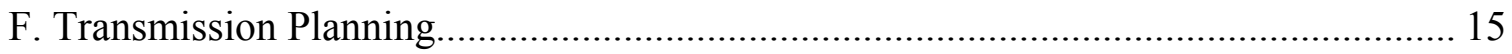

IV. Climate Policy Obligations .......................................................................................................... 17

A. The Fat Tails Problem.......................................................................................... 17

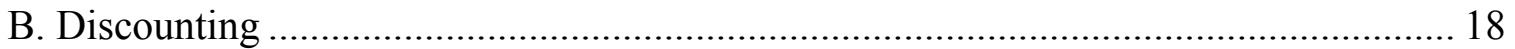

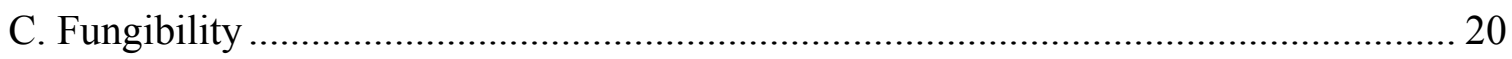

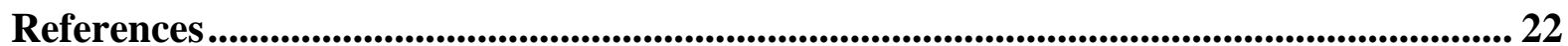




\title{
The Challenges of Climate for Energy Markets
}

\author{
Timothy J. Brennan*
}

\section{By Way of Introduction}

To set the stage, it is useful to begin with a biographical note. Prior to the mid-1990s, most of my sector-specific work in regulatory economics had involved communications, focusing on telephony competition and broadcasting policy. In 1995, I began my affiliation with Resources for the Future (RFF) by undertaking a project to co-author a book on the then-nascent policy of opening electricity markets to competition (Brennan et al., 1996). I began this work thinking that electricity had to be easier than telecommunications - after all, isn't it just a matter of plugging in the lamp and flipping the switch?

It did not take me long to learn that electricity presents far more complex problems than telecommunications. Attempting to sort out the conceptual underpinnings and rationales for these problems occupied much of my research for the next few years. In 2003, I returned to my antitrust roots by serving, along with my academic position, as a part-time staff consultant to the Federal Trade Commission, one of the U.S. national competition agencies. There, I started focusing on controversies in approaches to dominant firm conduct, particularly loyalty and bundled rebates. In 2006, I began a year as a visiting research economist in Canada's federal antitrust agency, the Competition Bureau. I spent that year working on dominant firm conduct as well as mergers, legislative review, telecommunications deregulation - and nothing involving electricity.

When I returned to the United States in 2007, I had the good fortune to hear Severin Borenstein, a leading academic expert in electricity policy at the University of California, talk about the costs and benefits of residential photovoltaic panels. Feeling like I'd missed much of

\footnotetext{
* Professor, Public Policy and Economics, University of Maryland Baltimore County, Baltimore, MD, USA, and Senior Fellow, Resources for the Future, Washington, DC, USA. Email: Brennan@umbc.edu. This paper was written at the invitation of Darryl Biggar and Robert Albon to present at the $10^{\text {th }}$ Australian Competition and Consumer Commission Regulatory Conference (Surfer's Paradise, Queensland, Australia, July 30, 2009). I want to thank them for the invite and for helpful comments. This work has benefited enormously from discussions of these issues with RFF colleagues, especially Molly Macauley, Karen Palmer, Dallas Burtraw, Shalini Vajjhala, and Alan Krupnick, and comments from Ingo Vogelsang at the ACCC Conference. Responsibility for all errors of omission and commission here is mine alone.
} 
the discussion over the past four years, I asked Severin what had become the big issues in electricity. He gave me a three-word answer: "It's all climate." Since then, electricity policy has become, if anything, more prominent in the climate debate. Even smart grid policies, originally intended to reduce the need for infrequently used and thus relatively expensive peak-power units, are being justified as a way to mitigate greenhouse gas (GHG) emissions, either by reducing demand or as adaptations to variability of non-fossil fuel power sources, such as wind and solar.

Anyone interested in this sector needs to become something of a climate expert. Recognizing that, I have nothing to offer on the science of climate change, and certainly have no reason or inclination to challenge the scientific consensus that it is happening and likely faster than forecast just a few years ago. I approach this issue not as a utility or energy company executive faced with the problems of planning and raising capital for future investments in light of the realities and the uncertainties in both the climate and the public policies designed to adapt and mitigate its effects. Nor do I consider myself an energy or environmental specialist, especially when compared with my RFF colleagues - although as a researcher at RFF, I have the opportunity to work among some of the leading climate change economists in the United States. ${ }^{1}$

Instead, I bring to the table the background that many in the ACCC have, that of an industrial organization economist. This brings not just the IO economist's stereotypical focus on the efficiency of markets, the likelihood of market failure, and the effects of methods to regulate prices and organization structure. It also means that one can take advantage of outsider status to challenge some of the often-implicit presumptions in the climate and energy efficiency policy conversation. Along with this disciplinary background, however, I also try to bring in learning from the philosophy of economics. Climate policy invokes not just economics but also ethical questions regarding the standing of future generations and the reduction of environmental benefits to willingness-to-pay.

Reflecting this background, I will discuss six of the challenges that climate change raises for energy markets from an economic perspective:

- Cap-and-trade vs. taxes

\footnotetext{
${ }^{1}$ Three current or former RFF economists are currently holding prominent positions in the Obama Administration. One is the chief climate economist on the presidential staff, working for Lawrence Summers, director of the National Economic Council; a second is the Undersecretary of Treasury overseeing climate policy there; and a third is the new director of the Energy Information Administration, the government's primary data source on energy use and forecasts.
} 
- Non-price regulations

- Energy efficiency policies

- Mitigation vs. adaptation

- Trade effects

- Transmission planning

I will then turn to three issues in the climate discussion that affect not how to face obligations to deal with climate change, but how to determine the scale of those obligations:

- The "fat tails" problem

- Discounting

- Evaluating policies by willingness to pay

Before turning to those, I want to first indulge my outsider perspective and offer some cautionary thoughts on how the climate discussion is often framed.

\section{First, a Quiz}

Aspects of how climate and conservation issues are presented that seem completely natural to the environmental and energy policy community look can look peculiar from the perspective of an economist who studies markets and market failure more generally. I can illustrate this with a four-question quiz.

Question 1: A common saying among energy conservation advocates is "The cheapest power plant is the one you don't build." Would you similarly infer that ...

a) The cheapest school is the one you don't build?

b) The cheapest vaccine is the one you don't administer?

c) The cheapest regulatory conference is the one you don't hold?

Answer: No, I trust. Any reasonable assessment of a school, vaccine, conference, or power plant would factor in the benefits as well as the costs. To infer policy merit from this sort of claim requires an assumption that the benefits of the electricity generated by the power plant are nonexistent. Many in the energy policy community who are not economists appear to believe this. The reasons seem to be that consumers' preferences for electricity use or against 
conservation technologies lack standing, or that they would use less electricity if only they had the information and wisdom of the experts. Economic tests, such as cost-benefit analyses, that base policy on revealed consumer preferences, typically reject both of these reasons. ${ }^{2}$

Question 2: Suppose someone goes to see An Inconvenient Truth, the movie that former U.S. presidential candidate and Vice President Al Gore made to increase public awareness of the potential harm from climate change. After seeing the movie, out of concern that she does her part to save the planet, she goes out and changes all the light bulbs and appliances in her house to devices that use less electricity and reduce her carbon footprint. In energy policy circles, what do we call this selfless, concerned individual?

Answer: A “free rider"! Yes, someone willing to make sacrifices to reduce her carbon footprint — or, for that matter, someone who makes the effort to calculate that she'd make out better in the long run by using compact fluorescent lighting or installing a high-efficiency airconditioner - is designated by the same term used to denigrate someone who takes advantage of others by refusing to chip in to supply a public good. The reason is that these actions are assessed purely on the basis of the effects of utility companies' energy efficiency subsidy programs. If someone, such as the person in the question, had switched technologies absent the subsidy program, she would get the benefit of reduced prices without a change in behavior. Thus, in industry parlance, she is a "free rider" on the subsidy. If you don't want to be thought a free rider, be either selfish or lazy.

Question 3: Suppose we have policies directed toward the goal of reducing GHG emissions. Two examples discussed in the United States and Australia are marketable emissions permits and (usually tradable) requirements that a statutorily designated percentage of energy be generated by renewable fuels such as wind, biomass, passive solar, or sometimes hydroelectric. ${ }^{3}$ What would you call these policies?

\footnotetext{
${ }^{2}$ For a consideration of how one might do cost-benefit analysis of energy efficiency programs if consumers suffer from some failure of choice that leads to individually suboptimal decisions, see Brennan (January 2009).

${ }^{3}$ Attending interagency electricity policy meetings while serving on the White House Council of Economic Advisers senior staff in 1997, I learned that hydroelectric power was not then considered a renewable fuel because of the environmental consequences of dam construction. "Renewable" may be as much a term of art in politics as it may be in physics.
} 
Answer: "Complementary"- or at least you would call them that if you were part of the U.S. climate discussion. ${ }^{4}$ But when two activities generate the same outcome, the more one has of the first, the less one needs of the second. In economics, these are substitutes. Were the more accurate term employed, it would illuminate the idea that legislating is to choose among alternatives. Leaving political realities aside, the economic choice is simple-figure out how to get prices to incorporate the external harms of climate change, and let producers and consumers adapt by choosing the technological and conservation options that best meet their needs taking the cost of climate effects into account. Legislators, though, gain not by making choices but by maximizing the spread of benefits, which the misleading designation "complementary" facilitates. ${ }^{5}$ Employing multiple paths ensures that the widest possible array of potential political backers will benefit from legislation, likely at the expense of consumers and the economy at large.

Question 4: While we're on the subject of political support, what does one call structuring climate change legislation to provide benefits to industries on the basis of claims that they would be harmed if they had to pay, directly or indirectly, to pollute?

Answer: "Competitiveness." As discussed below, the (likely) possibility that one country fails to adopt climate policies, and thus can export products at prices below the true marginal cost of production, may warrant adaptive pricing or trade policies in countries that undertake significant climate policies. These trade policies are justified only to reduce distortions, not to keep firms whole. Paul Krugman said in 1993, "If we can teach undergrads to wince when they hear someone talk about 'competitiveness,' we will have done our nation a great service" (Krugman, 1993). That lesson continues to be true.

\footnotetext{
${ }^{4}$ See, for example, the Pew Center for Global Climate Change Congressional Policy Brief Series website, http://www.pewclimate.org/congressional-policy-brief-series.

${ }^{5}$ I know about this linguistic trick because it is a staple of academic faculty, even if not especially economists, attempting to get articles published. One very often finds that a prior article covers the same topic in the paper one wants a journal to accept. The usual tactic is to say that the latter paper "complements" the former in that while it covers exactly the same ground, it does it by a somewhat different route. However, if that former paper had not been published, the case for publishing the latter paper would clearly be stronger, making them substitutes, not complements.
} 


\section{Economic Challenges}

With those lessons supplying some perspective, we can briefly examine the challenges climate policy presents for energy markets, beginning with half a dozen on the economic side.

\section{A. Cap-and-Trade vs. Taxes}

Assuming that the United States is going to engage in broad climate policy, the most hotly debated issue is whether the primary policy instrument should be a "carbon tax" on $\mathrm{CO}_{2}$ and perhaps other GHG emissions, or a cap-and-trade (CAT) system, like the Carbon Pollution Reduction Scheme proposed for Australia (Department of Climate Change, 2008). Under the latter, the government would set an overall limit on the carbon that the country could use, and issue or auction permits to emit $\mathrm{CO}_{2}$ that entities could market. A tax creates an incentive to reduce emissions or energy use because one avoids paying the tax, either directly or as it becomes embedded in goods such as electricity or gasoline. Under CAT, the permit price provides the same incentive as a tax, where reducing emissions either reduces the need to purchase permits or allows one to profit from the sale of a permit no longer needed.

Although the two have broadly similar properties, economists have identified two leading reasons why one might prefer tax to CAT or vice versa. ${ }^{6}$ The most important criterion comes from an analysis by Martin Weitzman published 35 years ago (Weitzman, 1974). Absent uncertainty regarding the marginal cost of reducing emissions through either abatement or reduced consumption, CAT and taxes are equivalent; one can hit a desired pollution price by setting the permit quantity under a CAT, and one can hit a designated emissions target by setting the price under a tax.

If the costs of reducing emissions are uncertain, whether one uses taxes or permits matters, with the costs of potential error depending on how the harm from pollution arises. Essentially, if the harm from pollution is trivial until a critical value is hit, after which point the harm becomes great, a permit program is better, since one can guarantee staying below the critical value regardless of the cost of reducing emissions. To the degree the marginal harm per ton of a pollutant is relatively constant, a tax equal to that constant harm is better, since

\footnotetext{
${ }^{6}$ Other issues not discussed here include the potential relative effects of taxes and CAT programs in terms of difference in ability to bank them and borrow permits against the future, how to count practices such as planting more trees for carbon sequestration, and baselines in determining whether to offset emissions by paying for low-cost GHG reductions in less developed countries.
} 
producers and consumers will internalize the right price in their decisions whether abatement is expensive or cheap. ${ }^{7}$

A second difference is associated with the tax vs. CAT debate but is more precisely about CAT implementation. Imposing a penalty on emissions, under either a tax or CAT program, seems obvious from an economic perspective, since it would lead people to take the cost of emissions into account. As many have pointed out, if there are other taxes in an economy, the "theory of the second best" may provide an argument for limiting and perhaps not even having emissions control programs (Parry and Oates, 2000). ${ }^{8}$ If the price of one good or service is too high, one wants to increase the price of substitutes and decrease the price of complements to reduce the distortionary effect of the initial price. Goods associated with pollution, particularly energy use, may be a complement to labor and the use of goods that one buys with (taxed) earned income. Because of widespread high rates of taxation of returns to labor and the purchase of goods from labor income, we would want to subsidize energy use; taxing it exacerbates the distortions from those preexisting taxes.

To avoid this outcome, the revenues from emissions controls should be used to offset and reduce these other taxes. This can be done with a carbon tax and under CAT if the permits are auctioned by the government to provide the revenue to use for this purpose. If permits are allocated freely rather than auctioned, however, these revenues are unavailable. It is not impossible that these emissions taxes, although a first-best improvement, make matters worse in a second-best world.

Those concerns, while fascinating to economists, appear to play little to no role in the actual policy debate. Two political factors seem to be the main drivers. First is that under a CAT program, it is fairly easy to reward politically influential constituencies by giving them permits. In comparison, handing out checks from funds raised through carbon taxes would

\footnotetext{
${ }^{7}$ A variation on this theme is the "safety valve" proposal, in which the government sets a ceiling price on permits under CAT by committing to sell an unlimited supply of licenses at a specified price, to assure producers and consumers that permit prices will not go above that level of the cost of abatement or reduced consumption become too severe (Pizer, 2002). Although this is often portrayed as a device to mitigate business risk, it may better be understood in these terms as substituting a tax at the ceiling price for a CAT program, hopefully reflecting a judgment that the marginal harm from pollution is relatively constant at the safety valve price. Recent work has pointed out the advantages of setting a price floor if the reduced cost of abatement reduces the price of permits (Burtraw et al. 2009).

${ }^{8}$ The original article describing how distortions in one part of an economy should affect pricing policies in another is Lipsey and Lancaster (1956).
} 
probably be too blatant to be politically feasible. With these realities, the ability to compensate is an advantage of the CAT system, in that absent compensation for the politically powerful, desirable regulation might not be enacted. ${ }^{9}$ But whether the policy is desirable because of the need to stay below a critical GHG emissions level, or whether the revenues should be recycled to mitigate tax distortions, gets little mention.

A second political factor, perhaps specific to the United States, is that in the past 30 years, taxes have become almost impossible to defend rhetorically. The consequences of this denigration go beyond climate policy to all facets of public budgeting. The combination of small-government advocates' belief (incorrect as it turned out) that cutting taxes would "starve the beast" and a public willingness to believe that government should be free, was responsible for much of the huge public debt the United States has incurred since 1980 (Niskanen and Van Doren, 2004).

Because the word "tax" is virtually toxic in U.S. policy debate, I have been proposing the use of the term "atmosphere dumping fee." Fundamentally, there is nothing that distinguishes a carbon tax from a price one would have to pay a landowner to accept trash on a landfill. The difference is that because no one owns the air, there is no private, competitive market that can set the dumping fee, so the government has to do it. I confess not to hold out a great deal of hope that a simple rhetorical trick can raise the discussion above the level of a schoolyard playground squabble.

\section{B. Will Policy Achieve the Right Price?}

As noted during the quiz, carbon taxes and CAT programs are not the only policy options under consideration in the United States. Over the years, the national government and the individual states (which have authority over retail intrastate electricity markets) have enacted a variety of specific mandates or programs to influence consumer energy use. ${ }^{10}$

\footnotetext{
${ }^{9}$ This also supports a theory of why one would compensate parties who suffer losses following issuance of regulations - what in the US are called "regulatory takings," following a clause in Fifth Amendment of the US Constitution that says, "nor shall private property be taken for public use, without just compensation." See Brennan and Boyd (2006).

10 We noted above whether these should be considered complements to CAT or tax policies, or substitutes when they are not available.
} 
Some involve the energy use per unit of service. A first program affects automobiles. Under the Corporate Average Fuel Economy (CAFE) program, administered since 1975 by the U.S. National Highway Traffic Safety Administration, vehicles sold by automobile sellers in the United States have to meet an average miles-per-gallon (mpg) of gasoline standard of 27.5, a number that has remained fixed since $1985{ }^{11}$ The standard has been lower for light trucks, which in recent years has helped spur the sales of sport utility vehicles in the United States, going from roughly $20 \mathrm{mpg}$ in the mid 1980s up to about $22 \mathrm{mpg}$. Recent increases in gasoline prices, climate concerns, and interest in reducing oil imports, along with a change from a more conservative Republican to a more interventionist Democratic presidency, led the U.S. Congress to increase the standard to $35 \mathrm{mpg}$ by 2020 .

A second type of effect, appliance efficiency standards, is in the United States more of an information-based program. For example, the U.S. Environmental Protection Agency (EPA) has created the Energy Star program, in which it labels consumer appliances and electronics goods that "meet strict energy efficiency guidelines set by the EPA and U.S. Department of Energy" (U.S. EPA, n.d.). The program also will put the "Energy Star" label on newly constructed homes with such appliances. Related to this, as noted above, a number of states have encouraged or mandated electric utilities to subsidize the purchase of more energy-efficient appliances and technologies, such as compact fluorescent bulbs.

A third regulatory option involves the electricity generation sector. Some states have enacted, and the U.S. Congress is currently considering, rules to require that electricity generators produce a given percentage of their energy through the use of renewable fuels, such as wind, biomass, passive solar, and (in some case) hydroelectric power. The Australian government is considering draft legislation to create a similar policy, called the "Renewable Energy Target" (Department of Climate Change, 2009a). These programs, referred to in the United States as renewable portfolio standards (RPS), typically include a marketable component. If one utility can meet its RPS target more readily than another, it can go beyond the standard and sell "renewable energy credits" (RECs) to other utilities that can use the credits to meet the RPS. In legislation recently passed by one of the two U.S. houses in Congress, RECs could be obtained for reducing energy use under some difficult conditions.

\footnotetext{
$1127.5 \mathrm{mpg}$ is about 11.7 kilometers per liter. In the US, automobile fuel efficiency is measured in distance per fuel unit rather than fuel units per distances (e.g., liters per hundred km).
} 
Basic economics suggests that these programs would not be necessary if we were to simply get the price right, through a carbon tax or a CAT program. ${ }^{12}$ They have little independent justification and potentially significant costs, since complying with these regulations may distort behavior away from what consumers would prefer, even taking externalities from fossil fuel use into account. ${ }^{13}$ An additional consideration is that under a CAT program, a separate renewable use requirement will have no effect on the allowed overall level of emissions. Reduced emissions from greater use of renewables will increase the amount of fossil fuel emissions permissible under the ceiling, with the only effect being a reduction in the price of an emissions permit. Renewable requirements will reduce emissions only if emissions from other sources would be so low that total emissions would be below the allowed level-implying that permits would be free. In effect, a CAT program would then have no effect on emissions over and above the reductions created by the renewable requirement. ${ }^{14}$

Undoubtedly, these programs are the result of political influences; the renewables industry has its lobbyists, just as the oil and coal industries have theirs. ${ }^{15}$ Appliance use standards, moreover, need not reduce actual energy use, since they reduce the cost per unit of service and thus will lead to more intense use of the appliance and, not just conceivably, more energy use overall. ${ }^{16}$ Finally, implementation peculiarities in these programs could prove a boon to lawyers and expert economists rather than the environment. ${ }^{17}$ Nevertheless, if political forces

\footnotetext{
12 The Australian government appears to regard renewable requirements as a transition to carbon permit trading, which it calls "the economically responsible way to tackle climate change" (Department of Climate Change, 2009b).

${ }^{13}$ For a critique of CAFE standards on economic welfare grounds, see Kleit (2002).

${ }^{14}$ I thank Karen Palmer for this observation.

15 In the US, the term "lobbyist" is applied to a person representing an interest group in meetings and other occasions with legislators to persuade them to adopt legislation that the interest group supports. The term comes from the lobby of the Willard Hotel in Washington near the White House, where in the $19^{\text {th }}$ century these influence seekers would gather, although Wikipedia reports that the term has been used in England to refer to similar gatherings in the lobbies of the Houses of Parliament.

${ }^{16}$ For a model showing that if energy price is sufficiently high, increased energy efficiency will increase energy use (unless the technology increases consumer benefit with no energy used), see Brennan (May 2009).

${ }^{17}$ A good example is that in H.R.2454, the climate bill currently under consideration by the US Congress, which would mandate an RPS increase up to $20 \%$ by 2020 , electricity suppliers can apply electricity use reductions against an RPS only if those reductions "ensure that, except as provided in subparagraph (L), the retail electric supplier claiming the savings played a significant role in achieving the savings" (Amended Sec. 610(f)(1)(J)). One can imagine the litigation opportunities inherent in determining whether my installation of a high-efficiency airconditioner was or wasn't because of a utility's information or subsidy program.
} 
preclude efficient carbon pricing through either a tax or an effective CAT program, the legitimate demand for substitute — not complementary_-programs such as these may be greater.

\section{Energy Efficiency}

As mentioned above, among the central tactics for mitigating climate effects, with special emphasis on electric utilities, are policies to increase energy efficiency, defined as the quantity of energy services (heating, cooling, miles traveled) one gets from a given unit of energy input (megawatt-hour, BTU, gallon of gasoline). I have already discussed the possibility that such policies could reduce energy use. More generally, energy efficiency policies may and should be subjected to the questions in the preceding section, regarding whether they would be necessary if consumers faced the right prices.

In addition to those questions, the energy efficiency policy discussion introduces three other topics that potentially challenge the conventional insights economics would bring. A first is doubt in consumer rationality. Standard economics provides an argument for energy efficiency policy if energy itself is underpriced, as happens if climate externalities are not reflected in its price. Another possibility is that constant prices over time fail to capture the huge divergence in generation cost. Because capacity has to be in place to meet demand at all times, the cost of covering peak periods lasting less than 1 percent of the time per year may be many multiples of the average.

Many energy efficiency advocates believe that even if electricity is priced correctly or, as is popularly claimed, overpriced, people still consume too much. This belief requires the premise that consumers fail to act in their own self-interest by, for example, not investing in high-efficiency lighting or appliances that would quickly pay for themselves in reduced energy spending. Leaving aside the general challenge rationality failures bring to standard economic practice, they raise specific difficulties in evaluating energy efficiency policies. Standard economics tools, such as cost-benefit analysis, are predicated on the assumption that one can infer willingness to pay from preferences revealed directly or indirectly in the marketplace. ${ }^{18}$ If

\footnotetext{
18 If there is no market from which values can be deduced (e.g., comparing house prices in areas with clean air to those with dirty air), one may have to use survey methods, such as contingent valuation (Portney, 1994).
} 
marketplace behavior is mistaken and does not tell us true willingness to pay, the foundation of economic policy evaluation buckles. ${ }^{19}$

A second challenge presented by energy efficiency involves changes to utility regulation intended to bring it about. A leading example in the United States is what is called "decoupling." This term refers to divorcing the revenues an electric distribution utility earns from the quantity of electricity it distributes, fixing its profits to ensure that it does not lose money if its customers use less electricity. Decoupling challenges extensive work in regulatory economics that has shown the flaws in regulatory methods based on fixing profits instead of giving regulated firms a fixed price for the service they provide (Vogelsang and Finsinger, 1979; Brennan, 1989).

A utility that makes money from sales may withhold information that would reduce demand and subsidize only complements for its service. These conclusions are weak, however, in that utilities are unlikely to be unique sources for information on the consumer value of energy efficiency, and these results will not hold if local electric utilities also sell energy itself, which may be procured at wholesale prices above regulated retail rates, especially during peak periods (Brennan, 2008). The likely effect of decoupling is not economic but political - to prevent utilities from opposing energy efficiency regulations and laws.

Considering politics raises a third possibility. The motive for energy efficiency may not be improved overall economic performance of the sector. Rather, it may be a device for a regulator to exercise monopsony power - to hold prices below the competitive level — on behalf of its consumers against wholesale electricity generators. In many cases in the United States, individual state regulators may lack the legal ability or upstream market power to carry off such a tactic. Nevertheless, energy efficiency subsidies could enable a regulator to solve the problem facing any monopsonist, which is how to ration demand when prices are below the point where supply equals demand. Consequently, at the margin a regulator concerned only with consumer benefit and not overall economic efficiency would find it desirable to subsidize energy efficiency, even if the consumers it represents bear the cost of the subsidies (Brennan, May 2009). ${ }^{20}$

\footnotetext{
${ }^{19}$ For a detailed review of this issue and an evaluation of proposed methods for evaluating energy efficiency programs that do not rely on cost-benefit analysis, see Brennan, n. 2 supra.

${ }^{20}$ This result may be an important example of a more general tension in competition law- whether the goal should be to maximize consumer welfare or total welfare.
} 


\section{Mitigation vs. Adaptation}

In addition to the divides between carbon taxes and CAT, and between these incentivebased programs and more specific mandates, climate policy includes yet another bifurcation that affects regulated industries, consumers, and the economy at large. This is the bifurcation between mitigation and adaptation, or as one might say, the difference between spending to stop climate change and spending to cope with it (Ausubel, 1993). One might view these policies as substitutes, but it is possible that adaptation is economically feasible only if climate change effects are relatively small, making it a complement to effective mitigation.

The optimal tactic could involve a combination of both; whether that is so requires scientific expertise beyond the scope of this paper (and its author). However, one might expect a bias in the choices. To some degree, the benefits of adaptation are local rather than global. For example, reinforcing or moving oceanside structures to limit the effects of increased seawater levels on the coastline benefits the residents and economies of the region or country that undertakes such work. ${ }^{21}$ The benefits of mitigation, on the other hand, are inherently global. The effects of a country's reduction in GHG emissions will be felt around the globe, not just in that country, although some countries will benefit more than others (Easterbrook, 2007). Thus, one would expect efforts to be directed toward adaptation, although some participants in the climate debate believe it has been dominated by mitigation (Foster, 2009).

There is a third option not discussed here, and not yet part of the serious policy discussion in the United States - attempts to prevent climate change through geoengineering, making large-scale changes to the environment that would induce global cooling (Kunzig, 2008). Ideas along these lines include introducing pollutants into the atmosphere that reflect sunlight. The seeming advantage of geoengineering is that it is far less expensive than mitigation or adaptation. The risk is that the environmental modifications involve enormous empirical uncertainty and the possibility of trading one catastrophe for another. This turns the advantage of geoengineering into its own global risk - it is sufficiently inexpensive that one country might decide to take the risk on its own.

${ }^{21}$ For a compendium of local infrastructure adaptation projects, see Foster (2008). 


\section{E. Competitiveness vs. Leakage}

A fifth issue in climate economics with potential business implications, likely most applicable in unregulated sectors, involves international trade. Not every country is likely to adopt climate controls. Developing countries may argue, not without some justification, that such restrictions preclude growth opportunities that the wealthier developed world was able to exploit. In addition, they may take the view that developed economies, not them, put the $\mathrm{CO}_{2}$ in the atmosphere through a century of fossil fuel burning, hence it should be up to the developed world to bear the cost of preventing serious climate change.

Regardless of underlying ethical merit, the outcome would be and has been delayed adoption of climate controls from one region of the world while others impose costs on themselves through carbon taxes, CAT programs, or other more specific regulations. If one region adopts carbon controls and others do not, the terms of trade are distorted. The relative price of goods produced in the non-adopting countries will, all else equal, be lower than those using energy produced in controlling countries, compared with what the relative price would be had all countries adopted such controls. ${ }^{22}$

The policy concern created by this arises because enterprises in countries that adopt climate controls will be relatively more vulnerable to competition from imports. ${ }^{23}$ In and of itself, competition from imports typically generates greater benefits to consumers through lower prices than it harms less profitable domestic suppliers and displaced domestic workers. ${ }^{24}$ But that observation, like most observations, assumes that market prices reflect marginal costs. Here, the concern is that the price of imports is too low because the non-adopting country has insufficiently incorporated the marginal global harm from GHGs into its production costs. ${ }^{25}$ The

\footnotetext{
22 One can think of exceptions, for example, where Country X with carbon controls uses goods from Country Y, which does not, as an input, while Country $\mathrm{Z}$ without carbon controls uses goods made in Country W, which does.

${ }^{23}$ Whether this will apply to Australia apparently remains to be seen (Foley, 2009). According to 2007 data, Carbon Monitoring for Action ranks Australia the third-worst carbon emitter among significantly sized countriesonly Poland and South Africa are worse-in terms of carbon intensity, defined as pounds of $\mathrm{CO}_{2}$ emitted per megawatt-hour. See http://carma.org/dig/show/world+country.

24 This of course is easier to say if one isn't one of those less profitable suppliers or displaced workers.

${ }^{25}$ It is important for the argument that the marginal harms be global. If a country elects not to adopt prices to reflect the costs of local environmental externalities, it is at least possible that it does so because the willingness to pay to mitigate those effects is minimal. If Country $\mathrm{X}$ does not recognize these as costs but Country $\mathrm{Y}$ does, it is effectively willing to supply goods at a lower cost than Country $\mathrm{Y}$, and reallocation of supply from $\mathrm{Y}$ to $\mathrm{X}$ is putatively efficient.
} 
effect may be exacerbated if climate controls in adopting countries reduce the world price of fossil fuels, conveying an even greater competitive advantage to the non-adopting countries (Sinn, 2007). ${ }^{26}$

This can rationalize a number of policies that would not otherwise be economically justified. Among the options, the best would be to add a carbon-content tax to imports, set so that the price of the imported good is what it would have been had the exporting country applied the correct carbon tax. ${ }^{27}$ Whether this would be permissible under current trade agreements is at least arguable. ${ }^{28}$ If not, the "theory of the second best" can rationalize policies to subsidize domestic production at the margin, to reduce its price and the distortion in favor of imports created by the absence of carbon policy in the exporting country.

Carefully designed tariffs and subsidies have a legitimate economic justification if exporting countries do not impose carbon policies and that absence reduces consumption of domestically produced substitutes. The rationale for such policies is only that. It is not to compensate domestic suppliers for lost business. If domestic suppliers cannot compete under effective global carbon policies because their production is more carbon-intensive than that in an exporting country and thus more vulnerable, they deserve no more compensation than would any other firm that loses out to a lower-cost competitor. As noted in Question 4 in the above quiz, this discussion has fallen under the "competitiveness" umbrella. As such, it may turn into a payment to politically powerful domestic interests not to block otherwise desirable carbon policies.

\section{F. Transmission Planning}

A last issue, but one that may be of crucial interest to utilities and business planners, involves planning for transmission lines to deal with climate policy. ${ }^{29}$ If climate policy did

\footnotetext{
${ }^{26}$ I thank Ingo Vogelsang for making this point at the ACCC conference. Sinn's argument also suggests that if the supply of fossil fuels is inelastic, a carbon tax might have to be very high to induce an actual reduction in fossil fuel use.

${ }^{27}$ I do not think that imports should be subsidized if a country imposes a carbon tax or policy stricter than could be justified. Going beyond that level is essentially altruistic, which is ethically meritorious. It seems to me that from an economic perspective, that comes out as an additional cost of production in that country, and should be treated as such.

${ }^{28}$ For more on the relationship between climate policy and trade policy, see Frankel (2008). In discussions of this issue, I have heard this called a "border tax adjustment", apparently to avoid using the term "tariff".

${ }^{29}$ For an extended discussion of this issue in the Australian context, see Biggar (2009).
} 
nothing but reduce energy demand, transmission issues would become trivial, since less capacity would be needed. In the United States, however, a significant expectation, with or without explicit renewable fuel mandates, is that there will be major investments in wind and passive solar power plants (Vajjhala et al., 2008). These renewable resources are not where the population and energy demand are, nor are they where present energy sources, such as coal and natural gas, are located. The best location for wind resources is the north-central part of the country, with its weather extremes, while the best for passive solar power is the hot desert Southwest.

Along with the enormous expense associated with these transmission lines are other substantial business and policy challenges. A first is undertaking the planning necessary to have these lines constructed. I have heard it suggested that all the potential producers meet together with the transmission planners in the government and in regional transmission organizations, and share their information on the timing and capacity of their investments with each other. In most other contexts, this would be tantamount to felonious price fixing. This is part of a more general issue of whether the entrepreneurial independence necessary to realize the value of having a competitive generation sector is consistent with the exigencies associated with having to plan major transmission investments (Brennan, 2006).

Even if the transmission investments were in place, wind and solar present longer-term challenges to the operation and planning of the electricity grid. Both of these sources are notoriously variable. Not only is passive solar restricted to daylight hours, but it varies with cloud cover, even in the desert. Wind may be even more variable, creating special challenges not only for providing energy to follow load by the minute, but also for meeting bulk energy demand because of subtransmission-level wind generation by, for example, farm windmills. In addition, wind supplies and electricity demand are negatively correlated where electricity is needed for cooling (Nelson, 2009). Absent either backup dispatchable generation, probably requiring fossil fuels, or greater control over consumer electricity use to match demand to supply (e.g., by remotely shutting appliances off), these power sources may have limited benefits, making expensive transmission investments even more risky.

A longer-run problem involves the effect of climate change availability of the resources themselves. Some recent studies in the United States have raised the possibility that changes in climate could alter the locations where these weather-based energy sources are available (Electric Power Research Institute, 2008). Wind patterns may shift, rendering currently promising locations ineffective. Transmission line rights-of-way may be subject to more frequent flooding or falling trees during storms. The volatility of all of these sources may 
increase, exacerbating the problems of increased reliance on sources that cannot be dispatched to follow loads. Because transmission lines may last decades, the presence of climate itself not only induces the need for planning but can also make the outcome of that planning much riskier.

\section{Climate Policy Obligations}

We conclude with a brief look at three arguments that go beyond designing climate policy for meeting targets to what those targets should be: how much should we sacrifice to mitigate climate change? These three are the fat tails problem, discount rates, and the role of willingness to pay in determining how much the environment is worth.

\section{A. The Fat Tails Problem}

From an economic standpoint, determining the value of climate policy entails a conceptually straightforward comparison of the expected benefits of the policy with the expected cost. The benefits of the policy, in turn, are usually calculated in terms of the expected willingness to pay for the benefits. The conceptual simplicity, of course, belies the specific determination of values to assign to different contingencies and imprecision in the physical science used to assign probabilities to those contingencies. But in principle, there is a number out there, and getting the policy right is based on taking our best guess at it.

Martin Weitzman, cited above as the source of economists' understanding of the potential differences between price-based (carbon tax) and quantity-based (CAT) programs, has argued that the problem is more conceptually complex, with no relevant finite number to apply (Weitzman, 2007, esp. 715-19). Weitzman's argument has two main components. The first is that the appropriate probability distribution to characterize a finite set of observations or climatemodel simulations is not the normal distribution but a t-distribution, which has fatter tails than the former, most importantly on the side of catastrophic losses. The second is that if we apply standard utility models of constant relative risk aversion (CRRA), ${ }^{30}$ the expected utility from this inferred distribution from climate models is $-\infty$. In other words, we would better off spending any amount to eliminate the chance of climate change in the "fat tail" of the $t$ distribution.

\footnotetext{
${ }^{30}$ Essentially, constant relative risk aversion implies that the elasticity of marginal utility with respect to consumption or wealth is constant.
} 
Infinite costs or benefits tend to get a skeptical reception within a discipline that believes tradeoffs are a ubiquitous fact. I share that skepticism. I am not in a position to take on Weitzman's claim regarding the statistical reasonableness of the fat tail distribution itself. The use of CRRA models is more problematic, for reasons related to Weitzman's rejecting the normal distribution. The empirical applicability of CRRA models to human behavior comes from its use in characterizing how people relate to relatively finite gambles. To apply it to climate catastrophes is to take it far out of the sample for which it works. This is crucial because CRRA models tend to explode toward $-\infty$ as consumption falls to zero, making it unduly sensitive to fat tails.

Moreover, the logic behind the $-\infty$ seems to apply to private catastrophes as well as public ones, such as the likelihood of a fatal accident. However, persons typically are not willing to pay infinite amounts to reduce the likelihood of private catastrophes. The use of a finite value of a statistical life is predicated on the belief that cost-benefit analysis should reflect the public's risk preference. If the data tell us that people are willing to pay only $X$ to reduce the chance of a fatality or catastrophic loss by $\Delta p$, one should assign a statistical value to that loss of $X / \Delta p$ in assessing policies so that the government spends as much as but no more than we would as individuals to reduce a particular risk. If this generally accepted procedure is valid, Weitzman's $-\infty$ must have a flaw. That flaw is that a utility function that explodes as wealth approaches zero must not reflect personal behavior.

\section{B. Discounting}

A more familiar dispute among climate policy makers is the choice of the discount ratehow much future losses should be valued against present costs. The larger the discount rate, the smaller future losses are valued today, and thus the smaller the sacrifice that should be made today to avoid them. The effect is most notable the further in the future one is considering. A loss of $\$ 1,000$ a century from now is worth $\$ 1,000$ today at a $0 \%$ discount rate, $\$ 368$ at $1 \%, \$ 50$ at $3 \%$, and a mere $\$ 6.74$ at a $5 \%$ discount rate.

The centrality of the discount rate to disputes over climate policy is evidenced by William Nordhaus's comment on Nicholas Stern's report ("Review”) to the British government advocating strong action to mitigation climate change:

But these [aforementioned] points are not the nub of the matter. Rather, the Review's radical view of policy stems from an extreme assumption about discounting. Discounting is a factor in climate-change policy-indeed in all investment decisions - that involves the relative weight of future and present 
payoffs. At first blush, this area would seem a technicality. Unfortunately, it cannot be buried in a footnote, for discounting is the central to the radical revision. The Review proposes ethical assumptions that produce very low discount rates. Combined with other assumptions, this magnifies impacts in the distant future and rationalizes deep cuts in emissions, and indeed in all consumption, today. If we substitute more conventional discount rates used in other global-warming analyses, by governments, by consumers, or by businesses, the Review's dramatic results disappear, and we come back to the climate-policy ramp described above (Nordhaus, 2007, at 689, reviewing Stern, 2007).

Nordhaus specifically criticizes Stern's use of a near zero discount rate on the interests of future generations, leading to a $1.4 \%$ discount rate on climate investments. He argues instead that the relevant benchmark should be the empirical returns on real world investments, which is about $4 \%$, leading to a time rate of discount of $2.7 \% .{ }^{31}$ In short, Stern's view is that regard for future generations is a matter of ethics; Nordhaus argues that it should be inferred from market behavior.

It is easy to confuse ethics and economics here because both perspectives are valid. Nordhaus's market discount rate is relevant when we are choosing among policies to benefit future generations. It represents an opportunity cost of resources devoted to climate change. For example, if the rate of return on climate policy is $3 \%$, and the rate of return on ordinary investments is $4 \%$, we should be making those ordinary investments instead, with the proceeds reserved for future generations. If, say, the return on medical research is $5 \%$, then the benefits exceed the opportunity cost. It would produce more benefit for future generations to invest in medical research rather in less productive general capital investments.

Opportunity cost should not be confused with ethical obligation. Looking at opportunity cost tells us what sacrifices to make for future generations if we are inclined to do so, but market returns tell us nothing about whether we should be inclined to do so. The following example illustrates the distinction (Brennan, 1999). Suppose that human generations were nonoverlapping, like garden flowers. Each generation is born at the same time, lives for eighty years, and dies. There is no direct reproductive link between individuals in one generation and

\footnotetext{
31 There is some discounting because future generations are expected to be wealthier than we are, and thus the marginal utility of extra consumption in the future is less than that today. Thomas Schelling has observed that ethical arguments for wealthy countries to sacrifice today to benefit future generations through climate policy provide an even greater justification for similar sacrifices to increase wealth in poorer countries today, and that developing countries would prefer the aid now to investments in climate (Schelling, 1992, esp. 7).
} 
those in the next. In such a world, one might expect persons in each generation to treat climate or other environmentally provided resources as theirs alone to use - in effect, have a very high discount rate.

But nothing about that discount rate is ethically justified, since no generation has preferential ethical standing. Were all persons behind John Rawls's "veil of ignorance," not knowing in which generation they would live, they would adopt institutions that gave each equal standing in claims for resources, balancing exhaustion of some resources against increased knowledge or production of others (Rawls, 1971). Politically and economically, private attitudes regarding the future will affect the intensity of efforts to address climate change and other issues. A recent survey of U.S. policy concerns found that climate change ranks $20^{\text {th }}$ out of 20 concerns presented to U.S. residents (Pew Research Center, 2009). Such attitudes tell us a great deal about whether climate policies will be adopted but little about whether they should be.

\section{Fungibility}

The last point is one on which the difference between economists and noneconomists is most pronounced, because it gets to the heart of the economist's paradigm. The valuation of avoiding climate change in economics comes down to the willingness to pay to avoid it. Even measuring that under the best of circumstances is not easy. Knowing what the effects would be is hard. Since some possible effects are more than incremental, inferring valuations from market conduct makes matters even more difficult. The circumstances in which future generations will be living, and thus how much they are harmed by climate effects (such as increased populations of disease-carrying insects), may be radically different from those in the present (Schelling, 1992). Last and not least, some environmental amenities, such as preservation of an isolated remote area, may have no behavioral trail in the form of tourism or other expenditures, thus requiring the use of stated preference contingent valuation surveys to elicit the valuations that would normally appear as a market price (Portney, 1994).

But apart from this is whether the environment should be valued in terms of willingness to pay. As noted in the discounting discussion, this policy issue - and any, ultimately — is about ethics. Cost-benefit analysis is useful not just because one can do it but because it reflects an underlying norm that government should act as people would in their role as consumers, with any distributional consequences to be left to tax and welfare policies. This leaves open the question of whether environmental benefits should be similarly cashed out. One might, at minimum, demand that environmental protection be valued not with the willingness to pay people happen to have, but with what they would offer only after reflecting on their moral 
obligations (Sagoff, 1986). A stronger perspective comes from "deep ecology," which holds that the environment does not exist purely to satisfy the wishes of people but deserves on its own to be protected from abuse (Foundation for Deep Ecology, n.d.).

In mentioning these in conclusion, I do not imply an endorsement. The purpose is only to show that climate policy presents numerous challenges within the economics paradigm to consumers, businesses, and regulators. Understanding how those policies play out may require an appreciation of norms and standpoints outside the familiar boundaries of economic thinking. 


\section{References}

Ausubel, Jesse, "Mitigation and Adaptation for Climate Change: Answers and Question," in Y. Kaya, N. Nakicenovic, W.D. Nordhaus, and F.L. Toth (eds.), Costs, Impacts, and Benefits of CO2 Mitigation (Laxenburg, Austria: International Institute for Applied Systems Analysis, 1993): 557-84.

Biggar, Darryl, “A Framework for Analysing Transmission Policies in the Light of Climate Change Policies: Final Report," Australian Energy Market Commission, Second Interim Report (16 June 2009), available at http://www.aemc.gov.au/Media/docs/Framework\%20for\%20Analysing\%20Transmission \%20Policies $\% 20$ in $\% 20$ the $\% 20$ Light $\% 20$ of $\% 20$ Climate $\% 20$ Change $\% 20$ Final $\% 20$ Report \%20(Dr\%20Darryl\%20Biggar)-4803ab59-1e2a-4a10-84ed-66b07f4318ad-0.PDF.

Brennan, Timothy, “Regulating by 'Capping' Prices,” Journal of Regulatory Economics 1 (1989): 133-47.

Brennan, Timothy, "Discounting the Future: Economics and Ethics," in Wallace Oates (ed.), The RFF Reader in Environmental and Resource Management (Washington: Resources for the Future, 1999): 35-41.

Brennan, Timothy, “Alleged Transmission Inadequacy: Is Restructuring the Cure or the Cause?" Electricity Journal 19(4) (May 2006): 42-51.

Brennan, Timothy, “Night of the Living Dead' or 'Back to the Future'? Electric Utility Decoupling, Reviving Rate-of-Return Regulation, and Energy Efficiency," Resources for the Future Discussion Paper 08-27 (August 2008), available at http://www.rff.org/RFF/Documents/RFF-DP-08-27.pdf.

Brennan, Timothy, “Optimal Energy Efficiency Policies and Regulatory Demand-Side Management Tests: How Well Do They Match?” Resources for the Future Discussion Paper 08-46 (January 2009), available at http://www.rff.org/RFF/Documents/RFF-DP08-46.pdf.

Brennan, Timothy J., “Energy Efficiency: Efficiency or Monopsony?” RFF Discussion Paper 0920 (May 2009), available at http://ssrn.com/abstract=1408696.

Brennan, Timothy, and James Boyd, "Political Economy and the Efficiency of Compensation for Takings," Contemporary Economic Policy 24 (2006): 188-202. 
Brennan, Timothy J., Karen Palmer, Raymond Kopp, Vito Stagliano, Alan Krupnick, and Dallas Burtraw, A Shock to the System: Restructuring America's Electricity Industry (Washington: Resources for the Future, 1996).

Burtraw, Dallas, Karen Palmer, and Danny Kahn, “A Symmetric Safety Valve,” Resources for the Future Discussion Paper 09-06 (2009), available at http://www.rff.org/documents/RFF-DP-09-06.pdf.

Department of Climate Change, Government of Australia, "Carbon Pollution Reduction Scheme: Australia's Low Pollution Future: White Paper" (December 15, 2008), available at http://www.climatechange.gov.au/whitepaper/report/index.html.

Department of Climate Change, Government of Australia, "Fact Sheet: Australian Government's Renewable Energy Target" (June 2009a), available at www.climatechange.gov.au/renewabletarget/publications/pubs/fs-ret-update.pdf.

Department of Climate Change, Government of Australia, "Renewable Energy Target Scheme Design" (June 2009b), available at http://www.climatechange.gov.au/renewabletarget/publications/pubs/ret schemedesign.p df.

Easterbrook, Gregg, "Global Warming: Who Loses - and Who Wins," The Atlantic (April 2007), available at http://www.theatlantic.com/doc/200704/global-warming.

Electric Power Research Institute, Joint Technical Summit on Reliability Impacts of Extreme Weather and Climate Change (Palo Alto, CA: EPRI, 2008), available at http://www.nerc.com/docs/pc/riccitf/EPRI_NERC_PSERC0_1016095.pdf.

Foley, Meraiah, “Australian Emissions Trading Plan in Trouble,” New York Times (June 22, 2009), available at http://www.nytimes.com/2009/06/22/science/earth/22iht-climate.html.

Foster, Josh, "Urban Leaders Adaptation Initiative: Climate Resilient Local Governments," Climate Change Action Project, Albuquerque, New Mexico, USA (January 24, 2008), available at http://www.ccap.org/docs/resources/569/CCAP\%20Urban\%20Leaders\%20NPSG\%20109.pdf.

Foster, Josh, "Center for Clean Air Policy: Urban Leaders Adaptation Initiative," presentation at the Center for Urban Environmental Research and Education, University of Maryland Baltimore County, Baltimore, MD, USA (April 17, 2009). 
Foundation for Deep Ecology, "Deep Ecology Movement," available at http://www.deepecology.org/movement.htm, accessed July 6, 2009.

Frankel, Jeffrey, “Global Environmental Policy and Global Trade Policy,” Harvard, Kennedy School Working Paper RWP08-058 (October 29, 2008), available at http://ssrn.com/abstract=1354671.

Kleit, Andrew, “CAFE Changes: By the Numbers,” Regulation 25 (Fall, 2002): 32-35.

Krugman, Paul, "What Do Undergrads Need to Know about Trade?” American Economic Review: AEA Papers and Proceedings 83 (1993): 23-26.

Kunzig, Robert, "Geoengineering: How to Cool Earth—At a Price," Scientific American (November 2008), available at http://www.scientificamerican.com/article.cfm?id=geoengineering-how-to-cool-earth.

Lipsey, R.G., and Kelvin Lancaster, “The General Theory of Second Best," Review of Economic Studies 24 (1956): 11-32.

Nelson, Paul, "Planning Reserve Margin: A New Perspective,” Rutgers University Center for Research in Regulated Industries, $22^{\text {nd }}$ Western Conference in Advanced Regulatory Economics, Monterey, CA (June 19, 2009).

Niskanen, William, and Peter Van Doren, "Some Intriguing Findings about Federal Spending," Public Choice Society, Baltimore, MD (March 2004), available at http://economistsview.typepad.com/economistsview/files/niskanen_vandoren.pdf.

Nordhaus, William, "A Review of the Stern Review on the Economics of Climate Change," Journal of Economic Literature 45 (2007): 686-702.

Parry, Ian W.H., and Wallace E. Oates, "Policy Analysis in the Presence of Distorting Taxes," Journal of Policy Analysis and Management 19 (2000): 603-13.

Pew Research Center for the People \& the Press, Survey Reports: Economy, Jobs Trump All Other Policy Priorities in 2009" (January 22, 2009), available at http://peoplepress.org/report/485/economy-top-policy-priority).

Pizer, William A., "Combining Price and Quantity Controls to Mitigate Global Climate Change," Journal of Public Economics 85 (2002): 409-34.

Portney, Paul, “The Contingent Valuation Debate: Why Economists Should Care," Journal of Economic Perspectives 8(4) (Autumn, 1994): 3-17. 
Rawls, John, A Theory of Justice (Cambridge, MA: Harvard University Press, 1971).

Sagoff, Mark, "Values and Preferences," Ethics 96 (1986): 301-16.

Schelling, Thomas, "Some Economics of Global Warming," American Economic Review 82 (1992): 1-14, esp. 7.

Sinn, Hans-Werner, "Public Policies against Global Warming," CESifo Working Paper Series No. 2087 (August 2007), available at http://ssrn.com/abstract=1014027.

Stern, Nicholas, Stern Review Web Page, Background to Stern Review on the Economics of Climate Change (2007), available at http://www.hmtreasury.gov.uk/independent reviews/stern review economics climate c hange/sternreview backgroundtoreview.cfm.

US EPA, “About Energy Star,” http://www.energystar.gov/index.cfm?c=about.ab index.

Vajjhala, Shalini, Anthony Paul, Richard Sweeney, and Karen Palmer, "Green Corridors: Linking Interregional Transmission Expansion and Renewable Energy Policies,” RFF Discussion Paper 08-06 (March 2008), available at http://www.rff.org/focus_areas/features/Documents/RFF-DP-08-06.pdf.

Vogelsang, Ingo, and Jorg Finsinger, “A Regulatory Adjustment Process for Optimal Pricing by Multiproduct Monopoly Firms,” Bell Journal of Economics 10 (1979): 157-71.

Weitzman, Martin, "Prices vs. Quantities," Review of Economic Studies 61 (1974): 477-49.

Weitzman, Martin, "A Review of the Stern Review on the Economics of Climate Change," Journal of Economic Literature 45 (2007): 703-24. 